\title{
Absence of Epstein-Barr virus in testicular germ cell tumours: a study of 21 cases using in situ hybridisation
}

\author{
N J Trendell-Smith, A Agathanggelou, H Herbst, C M P Collins, N Rooney, \\ G Niedobitek
}

\begin{abstract}
Aim-To establish whether testicular germ cell tumours contain Epstein-Barr virus (EBV) and if so to provide further evidence for the hypothesis that EBV plays a direct role in the pathogenesis of testicular germ cell tumours.

Method-Paraffin wax embedded tissue blocks from 21 germ cell tumours including 12 teratomas and nine classic seminomas were examined by in situ hybridisation for the expression of the small EBV encoded nuclear RNA transcripts (EBER-1 and -2) using isotopic and nonisotopic probes.

Results-There was no EBER specific signal detectable in any of the testicular germ cell tumours examined by in situ hybridisation whilst a strong signal was observed in appropriate control sections. Conclusion-The absence of demonstrable EBER transcripts in testicular germ cell tumours make a direct role for EBV in the pathogenesis of these tumours unlikely. Other explanations for the epidemiological and serological evidence linking EBV with germ cell tumours need to be explored.

(f Clin Pathol: Mol Pathol 1995;48:M109-M110)
\end{abstract}

Keywords: Germ cell tumour, Epstein-Barr virus, in situ hybridisation.

Testicular germ cell tumours and Hodgkin's disease are among the most frequent malignancies afflicting young men in the 15 to 39 year age group. The epidemiologies of these tumours shows similarities including increasing incidence in Western countries, higher incidence in white, urbanised populations and upper social classes, relative infrequency among black populations, low but definite familial occurrence, and an early geographically acquired lifetime risk irrespective of later migration. ${ }^{1}$ Like Hodgkin's disease, testicular germ cell tumours occur with increased frequency in HIV infected individuals. ${ }^{2}$ Some of these epidemiological features point to the possibility of an infectious agent as a potential aetiological factor in the development of these tumours. Recently, an association of up to $50 \%$ of western Hodgkin's disease cases with the EpsteinBarr virus (EBV) has been established. ${ }^{3}$ This finding, together with the observation of increased titres of antibodies against the EBV encoded viral capsid antigen (VCA) ${ }^{4}$ in patients with testicular germ cell tumours, prompted us to study a series of 21 cases for the presence of EBV using a highly sensitive in situ hybridisation technique.

\section{Methods}

Twenty one cases of testicular germ cell tumours were collected between 1984 and 1990 from the files of the Bristol Royal Infirmary, Bristol. The ages of patients varied widely within a range from 19 to 71 years, the vast majority being between 20 and 40 years of age. The tumours were evenly distributed between right and left testes.

\section{HISTOPATHOLOGICAL EVALUATION}

All of the tumours were classified according to the British Testicular Tumour Panel and Registry Classification, ${ }^{5}$ using formalin fixed, paraffin wax embedded tissue sections stained with haematoxylin and eosin. An average of four blocks were taken from each testicular tumour with a range from two to six. If tumours were poorly differentiated or showed areas of trophoblastic or yolk sac differentiation, immunohistochemical stains were performed to confirm these observations. Histologically, the tumours were placed into five separate groups: teratoma differentiated (two cases), malignant teratoma intermediate (four cases), malignant teratoma undifferentiated (five cases), mixedmalignant teratoma intermediate and seminoma (one case), and classic seminoma (nine cases).

\section{EBV STUDIES}

In situ hybridisation

Digoxigenin and ${ }^{35} \mathrm{~S}$ labelled single-stranded RNA probes were generated by in vitro transcription from the plasmids pBSJJJ1 and pBSJJ2 harbouring the EBV encoded nuclear RNA transcripts EBER-1 and EBER-2 specific inserts, respectively. ${ }^{67}$ In situ hybridisation was carried out as described by Niedobitek et al. ${ }^{6}$ Briefly, $5 \mu \mathrm{m}$ tissue sections were dewaxed, rehydrated and treated sequentially with $\mathrm{HCl}$ and pronase. Hybridisation was carried out overnight at $50^{\circ}$. Slides were washed under stringent conditions followed by RNAse digestion to eliminate non-specific binding. Bound probe was visualised by autoradiography or using a digoxigenin specific 
monoclonal antibody and the alkaline phosphatase-antialkaline phosphatase (APAAP) technique. Sections from an EBV positive Hodgkin's disease case served as positive controls in all experiments. RNA integrity was assessed by in situ hybridisation with a ${ }^{35} \mathrm{~S}$ labelled $\kappa$ immunoglobulin light chain specific messenger RNA (mRNA) probe as described previously.

\section{Results}

There was no EBER specific signal seen in any of the testicular germ cell tumours analysed using in situ hybridisation. In all experiments, strong nuclear labelling of Hodgkin and ReedSternberg cells was observed in the control sections using the EBER specific antisense probes. No staining was seen with the sense control probes derived from the same plasmids. Control experiments with the $\kappa$ immunoglobulin light chain specific mRNA probe led to intense labelling of scattered plasma cells in all cases indicating that loss of RNA integrity did not account for the negative results obtained with the EBER specific probes.

\section{Discussion}

In this study we have demonstrated the absence of detectable EBER transcripts from the tumour cells of all 21 testicular germ cell tumours. Various lines of evidence have previously suggested the possibility of an association between this tumour type and EBV, including epidemiological similarities to Hodgkin's lymphoma ${ }^{8}$ and infectious mononucleosis, increased incidence in HIV positive patients and raised anti-EBV antibody titres. As far as we are aware, no previous studies have looked at the presence of EBV antigens or EBV transcripts in these tumours.

Although there is some epidemiological and serological evidence to support a role for EBV in the pathogenesis of testicular germ cell tumours, no direct experimental data is available to lend credence to this relationship. In 1988, Algood $e t a l^{4}$ demonstrated elevated titres of IgG antibodies to EBV VCA in over $80 \%$ of seminomas and non-seminomatous germ cell tumours. However, EBV is a ubiquitous virus infecting over $90 \%$ of the adult population world wide. ${ }^{9}$ Elevated EBV specific antibody titres may well reflect changes in the immune status of patients with testicular germ cell tumours and not necessarily indicate an aetiological role for EBV.

In situ hybridisation for the detection of the EBER transcript provides a sensitive means to address such a problem. The EBER transcripts are expressed at high copy number in the nuclei of latently EBV infected cells. ${ }^{10}$ Moreover, several studies have demonstrated that the EBER transcripts are expressed in all known conditions associated with latent EBV infection. ${ }^{11-14}$ The consistent absence of EBER transcripts from testicular germ cell tumours therefore strongly suggests that EBV is unlikely to play a major role in the pathogenesis of these tumours.

However, in view of the limited number of cases, the possibility of EBV infection in a small proportion of cases remains. Recently, the presence of EBV has been demonstrated in a small fraction of gastric adenocarcinomas ${ }^{7}$ and further studies of larger series will be necessary to exclude a similar relationship between EBV and testicular germ cell tumours.

1 Grigor KM, Pathology of testicular tumours. In: Chrisholm GD, Fair WR, eds. Scientific foundations of urology. 3rd edn. Oxford: Heinemann, 1990:632-41.

2 Wilson WT, Frenkel E, Vuitch F, Sagalowsky A. Testicular tumours in men with the human immunodeficiency virus. f Urol 1992;147:1038-40.

3 Herbst $H$, Niedobitek G, Kneb $M$, Hammel M, Finn T, Anagnostopoulos I, et al. High incidence of Epstein-Barr virus genomes in Hodgkin's disease. Am $\mathcal{F}$ Pathol 1990; virus genom

4 Algood C, Newell G, Johnson D. Viral aetiology of testicular tumours. F Urol 1988;139:308-10.

5 Pugh RCB. Pathology of the testis. Oxford: Blackwell, 1976.

6 Niedobitek G, Young LS, Lau R, Brooks L, Greenspan D, Greenspan JS, Rickinson AB. Epstein-Barr virus replication in the absence of a detectable latent phase. $\mathcal{F ~ G e n}$ Virol 1991;72:3035-46.

7 Rowlands DC, Ito M, Mangham DC, Reynolds G, Herbst $\mathrm{H}$, Hallissey MT, et al. Epstein-Barr virus and carcinomas: rare association of virus with gastric carcinomas. $B r f$ Cancer 1993;68:1014-19.

8 Nowell G, Mills P, Johnson D. Epidemiological comparison of cancer of the testis and Hodgkin's diesase among young males. Cancer 1984;54:1117-23.

9 Henle G, Henle W, Clifford P, Diehl V, Kafuko GW, Kirya BG, et al. Antibodies to Epstein-Barr virus in Burkitt's lymphoma and control groups. $\mathcal{F}$ Natl Clin Invest 1969; 43:1147.

10 Howe JG, Steitz JA. Localisation of Epstein-Barr virusencoded small RNAs by in-situ hybridisation. Proc Nat Acad Sci USA 1986;83:9006-10.

11 Niedobitek G, Herbst H, Young LS, Brooks L, Masucci MG, Brocker J, et al. Patterns of Epstein-Barr virus infection in non-neoplastic lymphoid tissue. Blood 1992;79:2520-6.

12 Herbst H, Steinbrecker E, Niedobitek G, Young LS, Brooks L, Muller-Lantzsch N, et al. Distribution and phenotype of Epstein-Barr virus harbouring cells in Hodgkin's disease. Epstein-Barr virus harb

13 Wu TC, Mann RB, Charache P, Hayward SD, Staal S, Lambe BC, et al. Detection of EBV gene expression in Reed-Sternberg cells of Hodgkin's disease. Int $\mathcal{f}$ Cancer 1990;46:801-4.

14 Wu TC, Mann RB, Epstein II, MacMahon E, Lee WA Charache $\mathrm{P}$, et al. Abundant expression of EBER-1 small nuclear RNA in nasopharyngeal carcinoma-A morphologically distinctive target for detection of Epstein-Barr virus in formalin fixed paraffin embedded carcinoma mens. Am 7 Pathol 1991;138:1461-9. 